\title{
The Effect of Bionic Brake Drum Striped Unit Body on Friction and Wear of Brake Pad
}

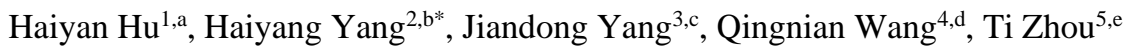 \\ 1,3 Jilin Business and Technology College, Department of Engineering, Changchun, China \\ ${ }^{2,4}$ Jilin University, College of Automotive Engineering, Changchun, China \\ ${ }^{5}$ Jilin University, College of Mechanical Science and Aerospace Engineering, Changchun, China
}

\begin{abstract}
In this paper, the contact mechanics is applied to analyse the interaction between the striped unit body on the bionic brake drum and the brake pad. The contact stress distribution law of two objects interaction is obtained. According to the stress distribution law the change of the friction and wear of the striped unit body on the brake pad is derived. Considering the change of the surface feature regardless of other factors, the friction wear of the striped unit body on the brake pad has increased by more than $27 \%$. It is found that small convex striped unit bodies are added on the surface of the bionic brake drum, which makes the contact surface between the brake drum and the brake pad no longer the original plane contact. Therefore, the pressure and direction between the contact surfaces are various. Besides, even if the external pressure does not change, the contact normal pressure between the contact surfaces will be increased which increases the friction wear on the brake pad accordingly.
\end{abstract}

\section{Introduction}

The braking of the truck is realized by the frictional resistance between the brake drum and the brake pad. The surface of the truck brake drum is an inner cylindrical surface. The surface of the brake pad is a part of the outer cylindrical surface. The brake drum is fixed on the truck wheel. It rotates with the wheel when the truck is moving. The brake pad is fixed on the truck body, which does not rotate when the truck is moving. During braking, the brake drum and the brake pad are pressed together under the action of external force. Both of them rub each other to generate frictional resistance and form a frictional resistance moment, which prevents the truck from moving and achieves the purpose of braking. The bionic non-smooth surface with different microstructure can be processed by the laser technology on the surface of metal material. This bionic shape feature can significantly improve the wear and thermal fatigue resistance of metal material, as well as realize the perfect combination of laser processing technology and bionic treatment, which has been proved by the Bionic WearResistant and Anti-Fatigue Research Group of Jilin University [1,2] through an amount of experimental researches.

After the bionic treatment of the brake drum, a hard convex unit body is formed on the surface of the brake drum. It can effectively reduce the wear of the bionic brake drum and improve its service life. However, the laser bionic brake drum increases the wear of the brake pad, reduces the service life of the brake pad, and increases the frequency of replacement brake pad. Therefore, it is necessary to study the friction and wear of the brake pad caused by the unit body to reduce the wear of the brake drum while taking into account the wear of the brake pad. Generally, there are three main types of the bionic unit pattern which are point, strip, and grid feature. In this paper, the friction and wear of the striped unit body on the brake pad has been discussed.

\section{The contact stress between the striped unit body and the brake pad}

For the analysis convenience, the surface of the striped unit can be supposed as a part of cylindrical surface and the brake pad surface is a plane surface. The contact between the striped unit body and the brake pad is the contact between the cylindrical surface and the plane, and the friction between them is the friction between the cylindrical surface and the plane. Therefore, the study is considered as the friction between the cylindrical surface and the plane. Considering the symmetry, the cross section is made perpendicular to the axis of the cylindrical surface to generate a diagram of the interaction between the cylindrical surface of the unit body and the plane of the brake pad, as shown in Fig. 1. \footnotetext{
aemail: huhaiyan@jlbtc.edu.cn, b*email: hyyang14@mails.jlu.edu.cn, cemail: yangjiandong56@126.com, demail:wqn@jlu.edu.cn,

Corresponding author's $b^{*}$ e-mail: hyyang14@mails.jlu.edu.cn
} 


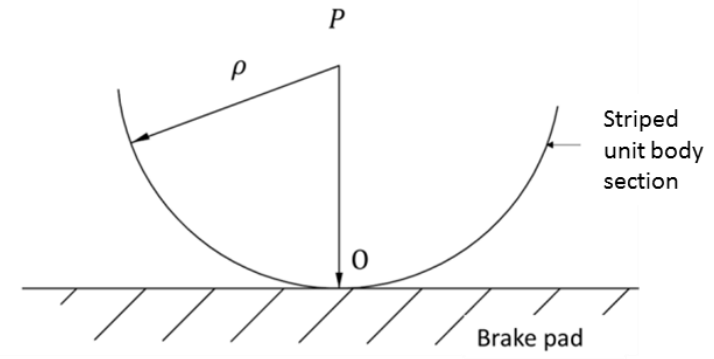

Figure 1. Cross-section diagram of the interaction between the striped unit body and the brake pad

The radius of the cylindrical surface of striped unit body is defined as $\rho$. P is the pressure of the unit body, which is perpendicular to the surface of the brake pad. $\mathrm{O}$ is the initial point of contact between the brake pad and the unit body. Under the action of the pressure P, the unit body and the brake pad will be elastically deformed. Considering that the striped unit body has been processed by laser quenching and has the high hardness, its deformation in braking is little and can be ignored.

It is assumed that the striped unit body surface is still cylindrical after being stressed. The brake pad will be elastically deformed under the pressure of the unit body. It forms the concave shape, and point $\mathrm{O}$ has been moved downward, as shown in Fig. 2.

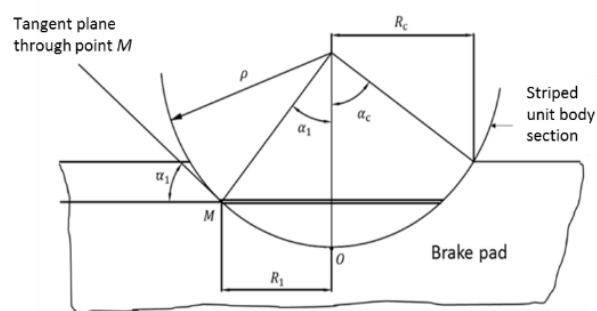

Figure 2. Diagram of the deformation of the brake pad under the action of the striped unit body

The plane surface of the brake pad is deformed into a concave cylindrical surface as same as the surface of the striped unit body under the action of the striped unit body. Therefore, the radius of the brake pad concave cylindrical surface is also $\rho$. The outer contour of the contact surface between the striped unit body and the brake pad is a rectangle. Accordingly, the length of the long side of this rectangle is same as the length of the cylinder and the length of the short side is the width of the indentation.

The indentation width is defined as 2RC (see Fig. 2). Considering that the length of the striped unit body is much larger than the width of the indentation, the contact between the striped unit body and the brake pad can be supposed as the contact of an infinite long cylinder with a semi-infinite plane. With such assumption, the relevant parameters of the unit length along the axis of the cylinder will be considered and the specific length of the cylinder will not be considered. The vertical line go down through the cylinder axis is the $\mathrm{Z}$ axis. This axis passes through the lowest point $\mathrm{O}$ of the contact surface between the unit body and the brake pad. Since the deformation of each point on the contact surface of the brake pad and the unit body is various, the contact stress on the contact surface is also various accordingly. The contact stress is changed according to the distance between the certain point and the $\mathrm{Z}$ axis, which is defined as R1. The contact stress is a function of R1

It is defined that $\mathrm{P}(\mathrm{R} 1)$ is the contact stress between the unit body and the brake pad on the contact surface along the cylinder axis direction of the unit length. $\mathrm{P} 0$ is the contact stress per unit length of the lowest point $\mathrm{O}$ of the contact surface between the unit body and the brake pad. Taking into account the point $\mathrm{O}$ on the brake pad during braking which has the maximum downward displacement and the biggest deformation, so that the stress P0 is maximum contact stress of both the contact surface based on the contact point $O$. According to contact mechanics [3], the contact stress P (R1) per unit length of a certain point $\mathrm{M}$ on the contact surface of a cylinder is:

$$
P\left(R_{1}\right)=\frac{2 P}{\pi R_{c}^{2}} \sqrt{R_{c}^{2}-R_{1}^{2}}
$$

\section{Friction and wear of the striped unit body on the brake pad}

Referring to the Preston equation [4], the amount of abrasive removal wear is calculated as,

$$
\Delta \mathrm{Z}=\int_{0}^{\mathrm{t}} \mathrm{kvp}_{\mathrm{n}} \mathrm{dt}
$$

where:

$\Delta \mathrm{Z}-\mathrm{The}$ amount of abrasive removal wear;

$\mathrm{t}$-Action time of the two in friction pair;

$\mathrm{k}$-Proportional coefficient;

$\mathrm{v}$-Relative speed of the friction pair;

pn - The pressure of the interaction between the friction pair.

Referring to the Fig. 2, take the $\mathrm{Z}$ axis as the center axis, there is an $M$ point on the contact surface. The distance between $\mathrm{M}$ and $\mathrm{Z}$ axis is $\mathrm{R} 1$. With the $\mathrm{M}$ point, a small micro unit has been considered with the width $\mathrm{dR} 1$. The value of $d R 1$ is extremely small. The pressure $\mathrm{dpZ}$ of the two cylindrical surfaces along the $\mathrm{Z}$ axis on this small micro element is the product of the contact pressure per unit length $\mathrm{P}(\mathrm{R} 1)$ and its width, which is

$$
\mathrm{dp}_{\mathrm{z}}=\mathrm{P}\left(\mathrm{R}_{1}\right) \mathrm{dR}_{1}
$$


By substituting equation (1) into equation (3), the result is

$$
\mathrm{dp}_{\mathrm{z}}=\frac{2 \mathrm{P}}{\pi \mathrm{R}_{\mathrm{c}}^{2}} \sqrt{\mathrm{R}_{\mathrm{c}}^{2}-\mathrm{R}_{1}^{2}} \mathrm{dR}_{1}
$$

Where the pressure dpz in the equation is along the $\mathrm{Z}$ axis in the vertical direction; the pressure of the interaction between the friction pair pn in equation (4) is along the normal direction of the contact surface. Since the contact surface between the two pairs is cylindrical and not horizontal, the tangent plane of point $\mathrm{M}$ is at an angle $\alpha 1$ to the horizontal plane, as shown in Fig. 2 .

Therefore, the pressure $\mathrm{dpZ}$ in the vertical direction in equation (4) should be used to obtain the pressure pn caused by the normal direction on the contact surface. Then by substituting pn into equation (2), the amount of friction wear caused by this element on the unit body can be calculated. Therefore, the point $M$ in Fig. 2 can be partially enlarged which is shown in Fig. 3

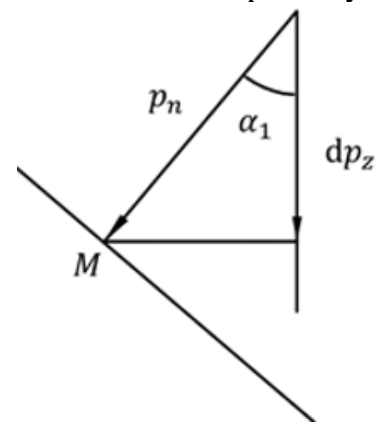

Figure 3. Magnified diagram of force on any contact point $M$

From the Fig. 3, it is shown that

And,

$$
\mathrm{p}_{\mathrm{n}} \cos \alpha_{1}=\mathrm{dp}_{\mathrm{z}}
$$

$\mathrm{p}_{\mathrm{n}}=\mathrm{dp}_{\mathrm{z}} / \cos \alpha_{1}$

From the Fig. 2, it is shown that

$$
\cos \alpha_{1}=\frac{\sqrt{\rho^{2}-\mathrm{R}_{1}^{2}}}{\rho}
$$

By substituting equation (4) and equation (6) into equation (5), the result is,

$$
p_{n}=\frac{2 P \rho}{\pi R_{c}^{2}} \sqrt{\frac{R_{c}^{2}-R_{1}^{2}}{\rho^{2}-R_{1}^{2}}} d R_{1}
$$

By substituting equation (7) into equation (2), the result is

$$
\Delta \mathrm{Z}_{1}=\int_{0}^{\mathrm{t}} \frac{2 \mathrm{kvP} \rho}{\pi \mathrm{R}_{\mathrm{c}}^{2}} \sqrt{\frac{\mathrm{R}_{\mathrm{c}}^{2}-\mathrm{R}_{1}^{2}}{\rho^{2}-\mathrm{R}_{1}^{2}}} \mathrm{dR} \mathrm{R}_{1} \mathrm{dt}
$$

The $\Delta \mathrm{Z} 1$ in equation (8) is the friction wear amount of the brake pad from the micro-element on the unit body. In order to calculate the whole wear amount $\Delta \mathrm{Z}$ on the brake pad surface by the striped unit body at the certain time $t$, the integration is performed in equation (8) for dR1. Referring to Fig. 2, considering about the symmetry, the $\Delta \mathrm{Z}$ is

$$
\Delta \mathrm{Z}=\int_{0}^{\mathrm{t}} \int_{0}^{\mathrm{R}_{\mathrm{c}}} \frac{4 \mathrm{kvP} \rho}{\pi \mathrm{R}_{\mathrm{c}}^{2}} \sqrt{\frac{\mathrm{R}_{\mathrm{c}}^{2}-\mathrm{R}_{1}^{2}}{\rho^{2}-\mathrm{R}_{1}^{2}}} \mathrm{dR} \mathrm{R}_{1} \mathrm{dt}
$$

Based on the equation (9),

$$
\begin{gathered}
\Delta \mathrm{Z}=\int_{0}^{\mathrm{t}} \frac{4 \mathrm{kvP} \rho}{\pi \mathrm{R}_{\mathrm{c}}^{2}} \int_{0}^{\mathrm{R}_{\mathrm{c}}} \sqrt{1-\frac{\rho^{2}-\mathrm{R}_{\mathrm{c}}^{2}}{\rho^{2}-\mathrm{R}_{1}^{2}}} \mathrm{dR}_{1} \mathrm{dt} \\
\Delta \mathrm{Z}=\int_{0}^{\mathrm{t}} \frac{4 \mathrm{kvP} \rho}{\pi \mathrm{R}_{\mathrm{c}}^{2}} \int_{0}^{\mathrm{R}_{\mathrm{c}}} \sqrt{1-\frac{1-\mathrm{R}_{\mathrm{c}}^{2} / \rho^{2}}{1-\mathrm{R}_{1}^{2} / \rho^{2}}} \mathrm{dR}_{1} \mathrm{dt}
\end{gathered}
$$

Considering that the brake pad is more rigid and has less elastic deformation, so R1 is small relative to $\rho$. The $\mathrm{R}_{1}^{2} / \rho^{2}$ in equation (10) can be ignored, and equation (10) becomes:

$$
\Delta \mathrm{Z}=\int_{0}^{\mathrm{t}} \frac{4 \mathrm{kvP} \rho}{\pi \mathrm{R}_{\mathrm{c}}^{2}} \int_{0}^{\mathrm{R}_{\mathrm{c}}} \frac{\mathrm{R}_{\mathrm{c}}}{\rho} \mathrm{dR} \mathrm{R}_{1} \mathrm{dt}
$$

Integrate formula (11) on $\mathrm{R} 1$ the result is,

$$
\Delta \mathrm{Z}=\int_{0}^{\mathrm{t}} \frac{4 \mathrm{kvP}}{\pi} \mathrm{dt}
$$

Comparing equations (12) and (2), it is indicated that the amount of friction wear caused by the bionic brake drum striped unit body on the brake pad has increased to $4 / \pi$, which is greater than 1.27 . This means that the amount of friction wear increases of the brake pad based on the striped unit body is more than $27 \%$.

\section{Conclusion}

This paper analyses the interaction between the striped unit body on the bionic brake drum and the brake pad, and obtains the contact stress distribution law of their interaction. Besides, the friction wear of the striped unit body on the brake pad according to the stress distribution law has been calculated. Regardless of other factors, just considering the changes in the surface shape, the amount of friction wear of the striped unit body on the brake pad is increased by more than $27 \%$. Although some assumptions and approximations have been made in the analysis, the results will have certain deviation, but the trend of change can be confirmed, which means that the striped unit body on the bionic drum will increase the friction and wear of the brake pad. For a traditional ordinary brake drum, its contact surface with the brake pad can be regarded as a plane contact, and the pressure is supposed as vertical to the plane contact surfaces uniformly. When a bionic brake drum is used in the brake, the pressure between the brake drum and brake pad shows no change macroscopically. However, due to the small convex striped unit bodies on the surface of the bionic brake drum, the contact surface between the brake drum and the brake pad is no longer in the plane contact. The magnitude and direction of the pressure between the contact surfaces have been changed. The magnitude and direction of the pressure between the contact surfaces have become variables. The original pressure does not represent the contact pressure between the surfaces. The contact pressure between the surfaces will be increased which increases the friction wear on the brake pad accordingly. This is a major reason that the bionic brake 
drum implementation will increase the friction wear of the brake pad.

\section{References}

1. J Dong. (2016) Influence of laser alloy bionic unit with $\mathrm{WC} / \mathrm{Cr}$ on fatigue wear resistance of gray cast iron. Jilin University, Changchun.

2. Z Liang. (2013) The effects of alloying enhanced bionic units on the tensile properties of lowcarbon steel, Jilin University, Changchun.

3. K.L. Johnson. (1992) Contact Mechanics. Cambridge University Press, Cambridge.

4. S Ji. (2011) Study on Machinability of Softness Abrasive Flow Based on Preston Equation. JOURNAL OF MECHANICAL ENGINEERING, 17.156-163. 